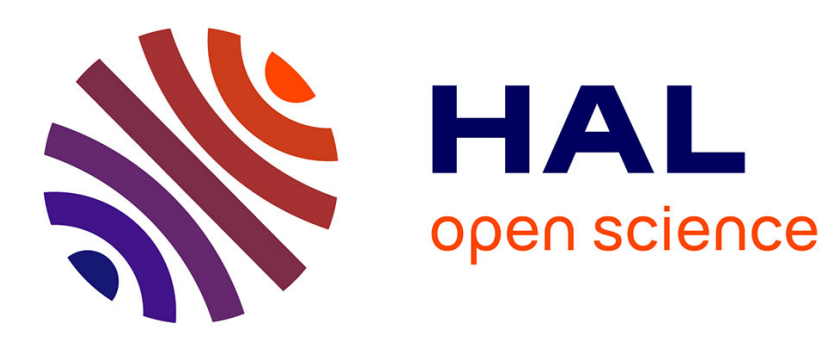

\title{
Changes in urban travel behaviour of elderly people
}

Pascal Pochet

\section{To cite this version:}

Pascal Pochet. Changes in urban travel behaviour of elderly people. Ortuzar J. de D., Hensher D. A, Jara-Diaz S.R. Travel Behaviour Research: Updating the State of Play, Pergamon, pp.299-316, 1998. halshs-00980864

\section{HAL Id: halshs-00980864 https://shs.hal.science/halshs-00980864}

Submitted on 18 Apr 2014

HAL is a multi-disciplinary open access archive for the deposit and dissemination of scientific research documents, whether they are published or not. The documents may come from teaching and research institutions in France or abroad, or from public or private research centers.
L'archive ouverte pluridisciplinaire HAL, est destinée au dépôt et à la diffusion de documents scientifiques de niveau recherche, publiés ou non, émanant des établissements d'enseignement et de recherche français ou étrangers, des laboratoires publics ou privés. 
Pochet P. (1998), Changes in urban travel behaviour of elderly people, in Ortuzar J. de D., Hensher D.A and Jara-Diaz S.R. (Eds), Travel Behaviour Research: Updating the State of Play, Oxford, Pergamon, pp. 299-316.

\title{
Changes in urban travel behaviour of elderly people
}

\author{
Pascal Pochet
}

\begin{abstract}
For a certain number of years now, France has been undergoing an ageing of its population. This ageing, which is going to become greater and continue over the coming decades is accompanied by profound modifications in the life styles of retired people. They are more and more motorised in the cities and less and less prisoners of the necessity to walk or use public transport. In this paper we will try to study the changes in the mobility of the elderly using diachronic data obtained from household surveys carried out in the seventies and eighties in the Grenoble conurbation. At analytical level, the factors explaining these changes can be linked to the renewal of the generations and the modification of the socio-economic environment which counter the ageing effects. We first situate the travel pattern and modal use evolution of elderly people within the context of the population as a whole. We then go on to deal with the central question in the evolution of the modal distribution, i.e. the individual's access to the private car, and its daily use. The longitudinal study of the successive cohorts enables us to visualise the differences in behaviour between men and women on the one hand, and the determining character of the development of car ownership for successive generations on the other hand. Using a breakdown of car driving into three effects (demographic, ownership and actual use of cars) we show that it is the increase in car ownership, much more than the other two effects, which leads to an increase in car driving after the age of sixty. The same type of analysis applied to people who are presently in the 40 to 60 age-group shows that women, who drive relatively little for the moment, are rapidly going to catch up in the future.
\end{abstract}

\section{INTRODUCTION}

Traditionally, elderly people cannot get about easily and they no longer travel for professional reasons. Over the last few years, however, their numbers, their life style, and their access to 
individual modes of transport have changed very considerably. These evolutions raise a certain number of questions which urban transport systems will be confronted with in the years to come:

- in a country with a high car-ownership level, will the ageing of the population, increased motorisation, and modifications in the behaviour of elderly people, lead to an increase or a decrease in the importance of the automobile for daily travel in the cities?

- what can the consequences of these changes be on the future of urban public transport, on the problems of traffic in cities, and on the satisfying of the travel needs of the elderly who cannot use this travel pattern?

In this paper we will try to study the changes in travel behaviour of the elderly using diachronic data obtained from household surveys. These changes can be explained by effects linked to the renewal of the generations and to the modification of the socio-economic environment which conflict with the effects which are due to ageing. We will first place the evolutions which concern elderly people in a wider context and then go on to deal with the central question in the evolution of modal distribution, i.e. the access to and the use of the private car. To study changes in behaviour, the more appropriate data are the panel surveys, but, as far as we know, in France they do not exist in the field of urban mobility. So we use household travel surveys carried out in Grenoble conurbation in 1978, 1985 and 1992. A longitudinal analysis of the different cohorts and a modelling of the growth of car driving using three parameters (demo-graphy, motorisation and actual driving) allow us to show that the growth of motorisation, rather than the other two parameters, leads to growth in driving. Using the same surveys carried out among people who are presently in the 40 to 60 age-group, we will show that women, who drive little for the moment, are more than likely to catch up over the next 10 to 20 years, as a result of increased motorisation and car-use.

\section{GENERAL CONTEXT}

In France, as in many industrialised countries, elderly people's place in society is undergoing very considerable change as the result of multiple factors whether they be demographic, sociological or economic. From the demographic point of view to begin with, the considerable lengthening of life expectation and the decrease in fecundity have come together to push up the percentage of elderly people in the population. Thus, the 1990 census shows that there were more than 11 million elderly people in France, i.e. almost one-fifth of the population. In the long term, if this evolution continues along the same lines, in 2010, one out of every four people will fall into this category. But this demographic fact needs to be interpreted correctly: for the same chronological age, elderly people's living conditions have been completely transformed over the last twenty years - improvement in the state of health ${ }^{\mathrm{i}}$ considerable increase in retirement revenues; so much so, in fact, that they are even higher than those of working people. However, despite these positive evolutions, the elderly population does not 
go to make up a homogeneous group. It is perhaps more a question of inequalities in cultural background, life expectation and state of health all brought together, which lead to such contrasting post-retirement situations, rather than differences in revenue. What has an eighty-year-old, living alone, with health problems and belonging to a generation which hardly knew the car, in common with a recently retired couple in full possession of their physical and intellectual faculties and who are fully active even if they no longer have any professional activities, and who, moreover, have a rich social-life and are car drivers?

More generally, this longer period of retirement has led gerontologists to consider two distinct periods in the life cycle of the elderly: younger pensioners, and older pensioners. Younger pension age is usually lived through in good health, in the company of the pensioner's companion, and can last, depending on individuals, till the age of 75 or indeed 80 . After that, older pensioners suffer from physical handicaps and a certain amount of social isolation, which severely limit travel patterns. Both of these periods of retirement are submitted to socio-economic change, to the renewal of the generations, and to the effects of ageing - but in very different ways.

\section{FRAMEWORK FOR ANALYSIS AND METHODOLOGY}

Various authors have shown that it is possible to classify the different factors which act on life-style evolutions and mobility into three categories: the effects of age; the effects of generation; the effects of period (Wachs, 1979; Kessler and Masson, 1985).

The effects of age cover several factors. There is first a continuous but non-linear process of individual ageing, be it physical or mental, along with the weight of experience acquired and habits inherited from the past. A certain amount of work of social orientation (Guillemard, 1972; Paillat, 1989) shows that daily activities at retirement age generally reproduce the activities which were already frequent in the past - new activities are rare. To this individual aspect of ageing we must add the discontinuities induced by the transitions in the life cycle and their specific social constraints.

Thus, for elderly people, the departure of children, retirement, or the death of a spouse can be events which determine their way of life and their mobility. In particular, for active people, retirement creates a vacuum of occupations and professional relationships, and these lead to a brutal reorientation of their field of activities. How they face up to this depends on their cultural background and the social position which they had acquired during their active period, and upon their ability to adapt.

The notions of generation or of cohort enable us to consider the individual's date of birth as just as important a variable as age for analysing social behaviour evolutions. The effects of generation or cohort are to be seen when one generation or more, because of their past, and 
their specific characteristics, adopt behaviour which is different from that of preceding generations at the same age. These inter-generation changes can be explained by an evolution of the economic environment of each generation.

The notion of period effects tries to integrate change which is linked to specific historic events and to the particular economic and social context of each epoch. For example, the growth rate of revenues, an improvement in the public transport system, a change in the relative prices of the various modes of transportation, can all be classified as period effects. For there to be a period effect, similar evolutions must therefore concern a large number of age groups and generations during the period under study.

From a prospective point of view, it is very interesting to try to distinguish the influence of the three effects - age, generation, period. Thus, the permanence of the effects of age enable us to highlight the invariable part of behaviour in time. Furthermore, generation changes which can already be seen amongst younger people should enable us to anticipate futures evolutions for the elderly. What is much more difficult to forecast are the effects of period linked to future variations in the economic and social environment. From a practical point of view, however, these three effects are not independent. It is not always easy to see where effects of generation stop and where effects of period begin. In particular, generations evolve under the influence of modifications in the socio-cultural environment, and this leaves a different mark on every generation as a result of its position on the age scale - the least elderly being considered as the most permeable to change. In the same way, the effects of age evolve under the influence of the renewal of generations and according to the period - on the contrary, generational differences can diminish with age.

In order to carry out the study of past evolutions, diachronic data was necessary. We use a series of household surveys carried out in the Grenoble conurbation in 1978, 1985 and 1992 (for certain aggregate results we have added in the results of a 1973 survey). Grenoble is one of the rare French cities which have been submitted to so many household surveys ${ }^{\text {ii }}$. Furthermore, the regular seven-year interval between the last three surveys makes the longitudinal study of successive seven-year amplitude cohorts possible. Finally, the Grenoble conurbation with 400,000 inhabitants proposes various transportation possibilities. There isan excellent urban transportation network cycling tracks ${ }^{\text {iii }}$. And despite these factors the car ownership rate is relatively high.

In this context, the evolutions in travel behaviour of elderly people must first be replaced within the context of the overall evolutions to be seen in Grenoble, if we are to hope to obtain a clear picture.

When we consider the population as a whole, the evolution over two decades shows an alignment of the travel models of men and women who have a high level of motorised mobility. The reasons for this evolution are now reasonably well-known. An example is the 
development of two-car ownership which is subtended by two tendencies which are highly characteristic of French society in the seventies and eighties:

- the spectacular growth of the rate of feminine activity. France is the European country with the highest number of women in full-time employment;

- the extension of suburbs as a result of people's preferring individual dwellings, and a widening out of the locations of activities, employment and equipment. One of the major consequences of this sub-urbanisation is a mean increase in commuting distances.

\section{MOBILITY AND USE OF TRANSPORTATION MODES: THE PARTICULARITIES OF ELDERLY PEOPLE}

\section{General Evolutions in the Use of Modes}

Over the last two decades, it is more than clear that there has been a very considerable evolution as a result of the ever-increasing domination of the private car over the other modes of transport, whether we consider women or men, and whatever the age group considered may be (cf. Figures 1a and 1c). Urban public transport is on the increase thanks to a considerable improvement in offer and quality of service. This growth has not been to the detriment of the car but rather to that of proximity modes such as walking and cycling. As far as the evolution concerning walking is concerned, it may be partly due to a variation in the area of the poll. In particular, in the case of Grenoble, the people living in the suburbs are more numerous in 1992 than in the 1985 poll. This does not however put the reality of a decrease over these 15 years into question, since this fall has been noted in other French cities (Orfeuil, 1992), German cities (Brög, 1992), and Canadian cities (Chapleau, 1989; Bussière, 1992). This decrease has gene-rally been to the benefit of the private car.

In this context, the evolution of the behaviour of people of sixty and over is logically a little behind. Here, the feminine travel model is very different from that of men (cf. figures $1 \mathrm{~b}$ and $1 \mathrm{~d}$ above). As far as women are concerned, car-use is very marginal indeed, and only to be observed amongst a certain category of women who were in salaried employment before retirement and whose socio-cultural level is high. On the other hand, retired men's level of car use is close to that of working men.

This behaviour mean must not be allowed to hide the very considerable differences which exist in the use of mode of transport after the age of sixty. These differences are not only due to sex, age and generation, but also to the action of other factors which may be linked to them, such as place of residence, the former socio-professional category, the level of education and matrimonial status. 
Figure 1

Comparative Evolutions in the Use of Modes of Transport for the Population as a Whole and for Elderly People

$a$ - Women of all ages

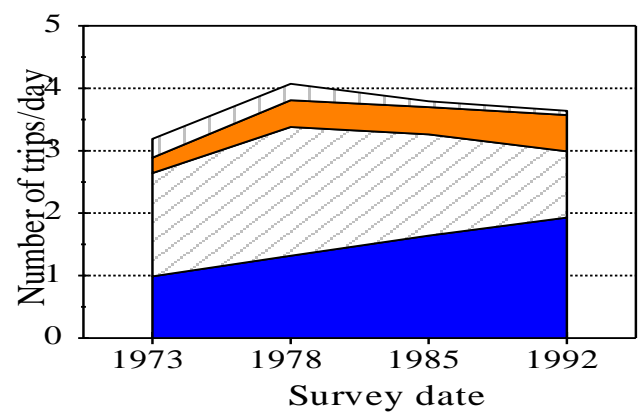

$\square$ Car $\square$ Walk $\square$ Public $\square 2$ wheels $c$ - Men of all ages

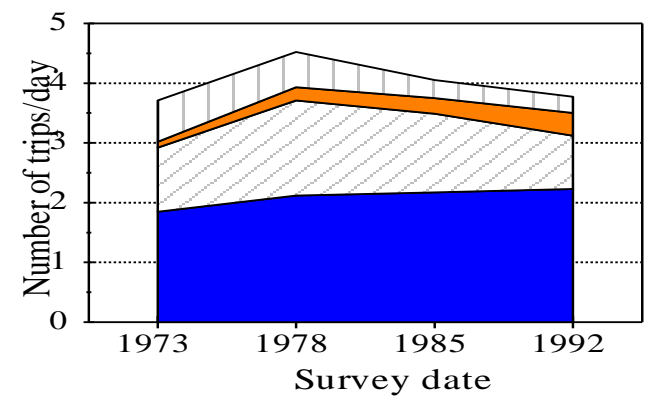

$\square$ Car $\square$ Walk $\square$ Public. $\square .2$ wheels $b$ - Women of sixty and over

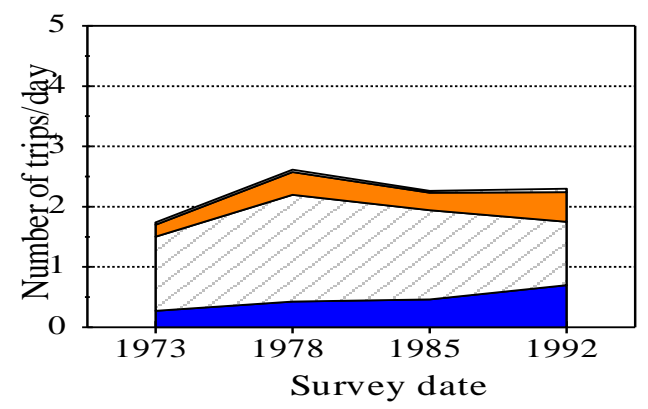

$\square$ Car $\square$ Walk $\square$ Public T2 wheels

$d$ - Men of sixty and over

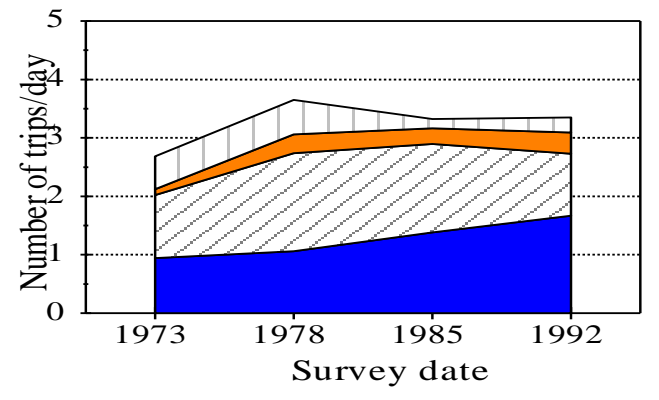

$\square$ Car $\square$ Walk $\square$ Public $\square 2$ wheels

\section{A Very Different Use of Modes of Transport by Elderly people}

With active people, the main constraints are temporal, these disappear or weaken upon retirement, and give way to space constraints. The activities undertaken outside home are now limited by the field of the places which can be reached, taking into account the level of car ownership and personal access to a car, as well as the public transport service available, and the person's state of health. These differences of course affect elderly people's daily mobility. Thus, the very old (over eighty) generally go out twice as little as people in their sixties. This also explains why proximity trips remain important for downtown residents, where the density of habitation, shops and equipment of all sorts are high. Thus, in 1985, on-foot mobility for downtown dwellers of over sixty in Grenoble was $80 \%$ higher than in the suburbs. Conversely, at the same date, elderly people who can drive use their cars twice as often when they live in the suburbs. The use of public transport becomes of paramount importance for non-motorised people. In particular, non-motorised women over seventy living in the suburbs 
made a quarter of their trips using public transport in 1985, whereas this proportion falls to less than 5\% for motorised men in the first half of their sixties. The former profession, and in a closely correlated manner, the level of studies and income, play a double role in travel behaviour. As far as these generations of people are concerned, it was the well-off who benefited most from motorisation. The most mobile potential drivers here are ex-professional men or -executives. Finally, the importance of matrimonial status is not so visible. In actual fact, it has little effect on mobility, whatever mode of transport is considered. On the other hand, it has a certain influence on car-driving for motorised women, as we shall see later.

Since we have now set out the general framework, we can now come back to the all-important question for the future - viz. the evolution of elderly people's car-driving in relation with the growth of car-ownership for successive generations of men and women.

\section{THE ELDERLY AND THE CAR}

\section{The Elderly and Motorisation}

The household surveys do not give us details about the real availability of a vehicle for the different members of the family polled. We will therefore refer to licence-holders whose household has at least one car as motorised persons, actual or potential drivers, or "drivers" for the sake of simplicity.

\section{Figure 2}

Reading Guide for Figures 3 and 4

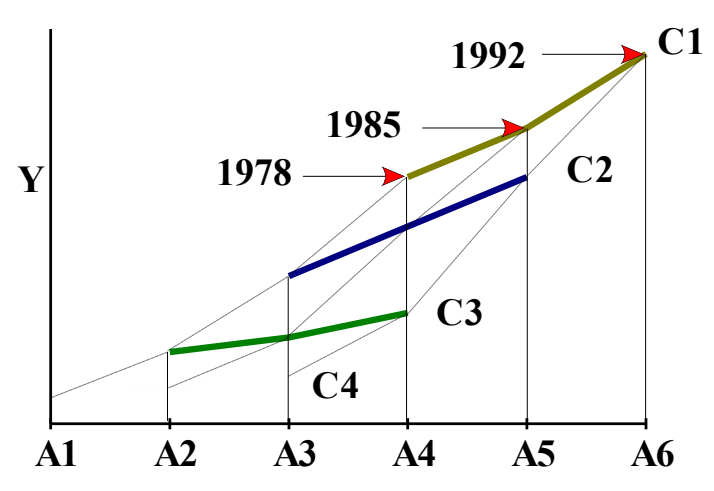

Y: Measure of travel behaviour

A1...A6: Age groups

C1...C4: Cohorts
Reading: Each cohort is logged by an interval of birth (7 years) and represented by the mean date of birth. The segments of the curve (profiles per cohort) enable us to follow the effects of ageing for each cohort between 1978, 1985 and 1992. For a given age, the vertical deviations between the cohorts enable us to measure the deviations from one generation to the next. 
If we look at the motorisation rates (Figures $3 \mathrm{a}$ and $3 \mathrm{~b}$ ) of the successive cohorts of men and women, we clearly see that the generalisation of the use of the car came about in cumulative fashion with the renewal of the generations, and it affected women much later than men. As Madre and Gallez (1992) show in French statistics series, the first wave of motorisation of households took place at the end of the fifties and through the sixties. This phase of massive introduction of the car can partly be assimilated to an effect of period, since it concerned a large number of generations, albeit to different degrees. Motorization was followed throughout the seventies and eighties by two-car ownership and the arrival of a considerable number of women on the employment and car-buying markets. This then explains why present generations of men from 60 to 80 (i.e. born between approximately 1910 and 1930) contain $60 \%$ to $80 \%$ actual or potential drivers. Conversely, the rate of motorisation of women from the same generations is two or three times smaller! The use that the two sexes make of the car is also very different.

Figure 3

Evolution of the \% of Potential Drivers for Each Cohort in Grenoble between 1978, 1985 and 1992

$a-$ Men

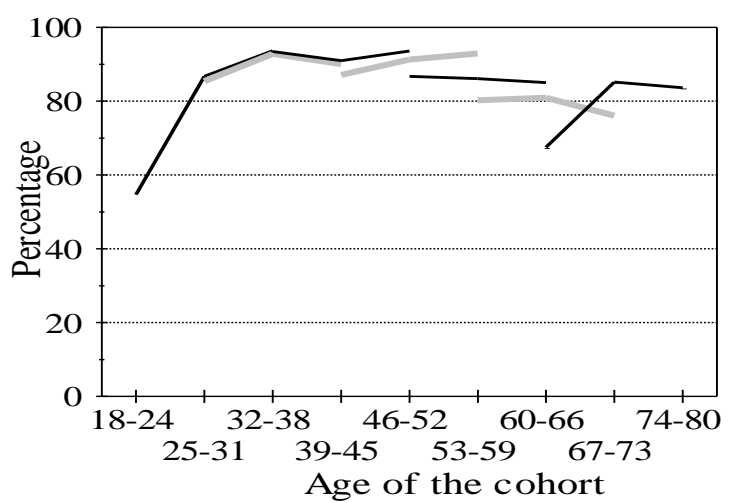

$b$ - Women

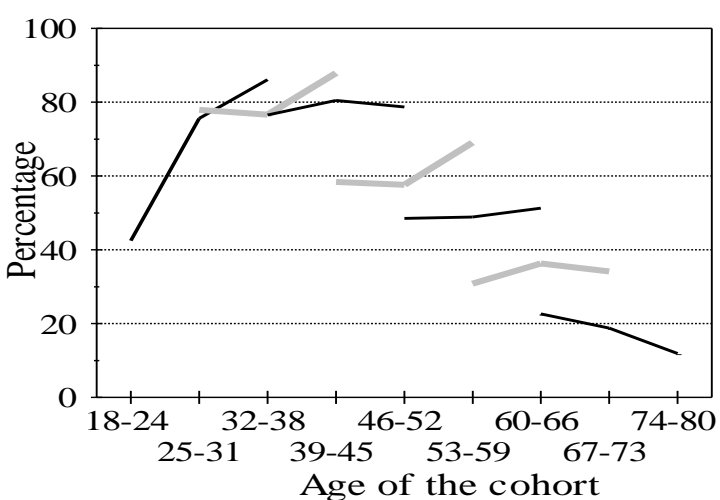

\section{Car Use in Different Generations of Drivers}

Figures $4 \mathrm{a}$ and $4 \mathrm{~b}$ show, for each cohort, and by sex, the evolution of the number of daily trips made at the wheel of a car by the actual or potential drivers of the sample. The high rate of overlap in the segments of the curves, taken along with their fall after the age of 60 show that the effects of age play an all-important role, specially by the important threshold represented by retirement. The only clear behaviour difference for motorised persons concerns the cohort of men who reach the age of 60-66 in 1992. 
The explanation for this surprising inflexion can partially be found in the residential localisation and the social make-up of this sub-group in the 1992 survey. In that year, $70 \%$ of the people polled in that age-group lived outside Grenoble, as against 54\% in 1985 and 30\% of them were former middle- or upper-executives, as against $20 \%$ in 1985 . As far as the evolution of feminine behaviour is concerned, women over 60 are not yet concerned, but women-drivers who either have children of school-going age or who are salary-earners, are especially those who concern us most, those in the 45-60 age group.

Figure 4

Evolution in the Number of Daily Car Trips for the Drivers in Each Cohort between 1978, 1985 and 1992

$a-$ Men

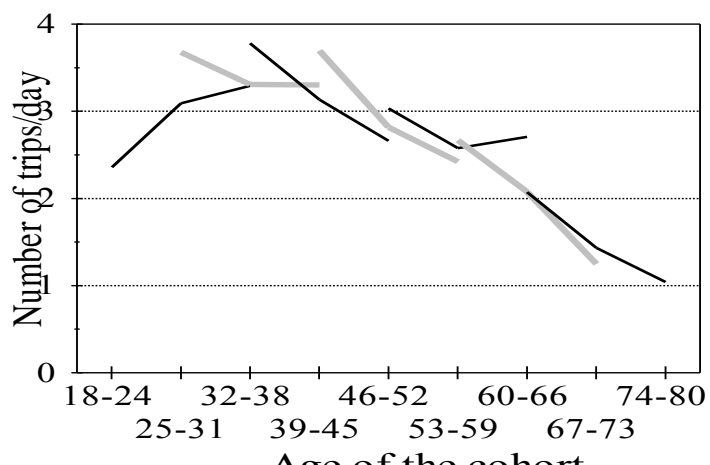

Age of the cohort $b$ - Women

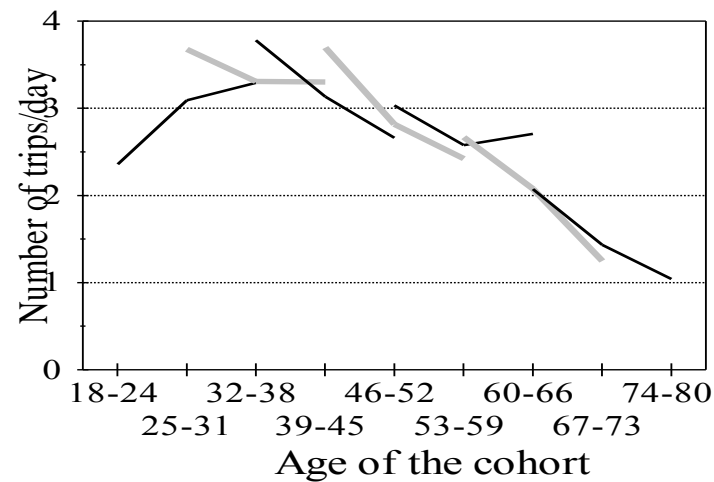

The other lesson which we can obtain from these figures is the persistence of the differences between sixty-year old men and women, once we have done away with the inequalities of car access. While actual or potential women drivers usually make on trip a day on average, men drivers are near to two trips a day, if not more. For the present generations of elderly people, the distribution of roles within the household appears to be relatively rigid, with the man as driver. Thus, elderly married women who are licence-holders are as often passengers as drivers in the family car(s).

\section{Formalising the Evolution in Car Driving}

In order to highlight the different effects in the evolution of car-driver mobility better, we have divided up the total volume of trips by age, according to the weight of each age, to the number of motorised persons in each age group, and to the mean number of daily trips made by "drivers" at the wheel for each age group (Greene, 1987). The evolution in the use of the car 
by a driver between date 1 and date 2 is therefore a ratio of the two sums of number of trips for all age groups i:

$$
\frac{C D 2}{C D 1}=\frac{\sum_{i} P i 2 C i 2 M i 2}{\sum_{i} P i 1 C i 1 M i 1}
$$

with $\mathrm{P}_{11}, \mathrm{Pi}_{2}$ : number of people in age-group $\mathrm{i}$ in dates 1 and $2 ; \mathrm{Ci}_{1}, \mathrm{C}_{\mathrm{i} 2}$ : percentage of drivers in age-group i (i.e. licence-holders whose household owns at least one car) in dates 1 and 2 , and $\mathrm{M}_{\mathrm{i} 1}, \mathrm{M}_{\mathrm{i} 2}$ : mean number of daily trips made by drivers at the wheel in dates 1 and 2 .

In order to measure precisely the influence of the demographic changes, the growth in motorisation and the evolution in the use of cars by drivers, the evolution of the mean number of car driver-trips can be considered as the product of:

$$
\frac{C D 2}{C D 1}=E(P) \times E(C) \times E(M) \times E(P, C) \times E(P, M) \times E(C, M) \times E(P, C, M)
$$

this is a "demographic" effect $\mathrm{E}(\mathrm{P})$ equal to the variation between dates 1 and 2 (where all the other variables have no incidence) of the number of people in each age-group, dependent upon ageing or deaths resulting from the two world wars. In the same way, there is a "motorisation growth" effect $\mathrm{E}(\mathrm{C})$ and a driver behaviour change effect $\mathrm{E}(\mathrm{M})$, which are respectively equal to:

$$
\begin{aligned}
& E(P)=\frac{\sum_{i} P i 2 C i 1 M i 1}{\sum_{i} P i 1 C i 1 M i 1} \\
& E(C)=\frac{\sum_{i} P i 1 C i 2 M i 1}{\sum_{i} P i 1 C i 1 M i 1} \\
& E(M)=\frac{\sum_{i} P i 1 C i 1 M i 2}{\sum_{i} P i 1 C i 1 M i 1}
\end{aligned}
$$

which are the three interaction effects of these factors taken two by two. Thus, for example $\mathrm{E}(\mathrm{P}, \mathrm{C})$ represents the demography/motorisation interaction effect:

$$
E(P, C)=\frac{\left(\sum_{i} P i 1 C i 1 M i 1\right)\left(\sum_{i} P i 2 C i 2 M i 1\right)}{\left(\sum_{i} P i 2 C i 1 M i 1\right)\left(\sum_{i} P i 1 C i 2 M i 1\right)}
$$


$E(P, M)=\frac{\left(\sum_{i} P i 1 C i 1 M i 1\right)\left(\sum_{i} P i 2 C i 1 M i 2\right)}{\left(\sum_{i} P i 2 C i 1 M i 1\right)\left(\sum_{i} P i 1 C i 1 M i 2\right)}$

$E(C, M)=\frac{\left(\sum_{i} P i 1 C i 1 M i 1\right)\left(\sum_{i} P i 1 C i 2 M i 2\right)}{\left(\sum_{i} P i 1 C i 2 M i 1\right)\left(\sum_{i} P i 1 C i 1 M i 2\right)}$

and, lastly, the interaction of the three factors taken simultaneously:

$\left.E(P, C, M)=\frac{\left(\sum_{i} P i 2 C i 2 M i 2\right)\left(\sum_{i} P i 2 C i 1 M i 1\right)}{\left(\sum_{i} P i 2 C i 2 M i 1\right)\left(\sum_{i} P i 2 C i 1 M i 2\right.}\right) \frac{\left(\sum_{i} P i 1 C i 2 M i 1\right)\left(\sum_{i} P i 1 C i 1 M i 2\right)}{\left(\sum_{i} P i 1 C i 2 M i 2\right)\left(\sum_{i} P i 1 C i 1 M i 1\right)}$

The interaction effects take into account the fact that the evolution in the number of trips is not only equal to the product of the pure factors, since the effects of variation of composition are taken into consideration as well. But the analysis shows that these interaction effects are quite unimportant, compared to the $\mathrm{E}(\mathrm{P}), \mathrm{E}(\mathrm{C})$ and $\mathrm{E}(\mathrm{M})$ effects.

These calculations were carried out between the 1978 and 1985 surveys on the one hand, and between the 1985 and 1992 surveys on the other hand - with the same division into age groups as those presented in the above figures. Furthermore, because of the considerable behaviour differences noted between men and women, these calculations have been carried out for both sexes. Finally, we studied separately, on the one hand the population of people of sixty and over and on the other hand people aged from 39 to 59, according to sex. The results indicating the importance of the principal effects in overall evolution are presented in Table 1 (for people between 60 and 66) and in Table 2 (for 39-59 years-old).

Table 1

Breakdown of Car Driving Growth for Men and Women of 60 and Over

\begin{tabular}{|lcccc|}
\hline & \multicolumn{2}{c}{ Men } & \multicolumn{2}{c|}{ Women } \\
& $1985 / 78$ & $1992 / 85$ & $1985 / 78$ & $1992 / 85$ \\
\hline Overall growth & $\mathbf{1 . 3 6}$ & $\mathbf{1 . 1 9}$ & $\mathbf{1 . 8 2}$ & $\mathbf{1 . 8 2}$ \\
Product of the 3 effects $P, C, M$ & 1.41 & 1.28 & 1.81 & 1.90 \\
Product of the 4 interaction effects & 0.97 & 0.94 & 1.00 & 0.96 \\
Breakdown: & & & & \\
$\quad$ "Demographic" effect P & 1.06 & 1.02 & 1.06 & 1.03 \\
$\quad$ "Motorisation" effect C & 1.28 & 1.11 & 1.55 & 1.44 \\
$\quad$ "Behaviour" effect M & 1.03 & 1.13 & 1.11 & 1.28 \\
\hline
\end{tabular}


The first result is the preponderance of the evolution of the motorisation and licence-holder rates in the overall evolution, compared with the demographic effect or the behaviour change effect.

Table 2

Breakdown of Car-Driving Growth for Men and Women of 39-59

\begin{tabular}{|lcccc|}
\hline & \multicolumn{2}{c}{ Men } & \multicolumn{2}{c|}{ Women } \\
& $1985 / 78$ & $1992 / 85$ & $1985 / 78$ & $1992 / 85$ \\
\hline Overall growth & $\mathbf{0 . 9 3}$ & $\mathbf{1 . 0 3}$ & $\mathbf{1 . 3 8}$ & $\mathbf{1 . 5 6}$ \\
Product of the 3 effects P, C, $M$ & 0.93 & 1.03 & 1.35 & 1.31 \\
Product of the 4 interaction effects & 1.01 & 1.00 & 1.02 & 1.00 \\
Breakdown: & & & & \\
$\quad$ "Demographic" effect P & 0.98 & 1.01 & 0.93 & 1.06 \\
$\quad$ "Motorization" effect C & 1.05 & 1.03 & 1.34 & 1.24 \\
$\quad$ "Behaviour" effect M & 0.90 & 0.98 & 1.09 & 1.19 \\
\hline
\end{tabular}

The evolution in the use of the car by "licence-holders" is greater between 1985 and 1992 for the sixties and over, especially as far as women are concerned. Furthermore, the interaction effects are somewhat limited, and the product of the three simple effects is close to the overall evolution. The only exception is for women of 39 to 59 between 1985 and 1992, for whom the combined effects are also important: demography/motorisation and demography/behaviour. These combined effects no doubt come from the drop in the size of age-groups during the second world war for whom motorisation and use progress less than in the other age-groups of forty-years-old.

Last but not least, these changes in the use of modes of transport are not only the reflection of increased motorisation, but even more so of more fundamental changes in life styles. These complex ways of life cannot be fully understood as a result of the household surveys which we have analysed. However, the activities which give rise to trips and which have been listed in the various surveys give us a certain number of indicators about the evolution of life styles after sixty. Commuting almost completely disappears for new generations of 60 years-old. This is not surprising since it has been possible to go into retirement at 60 rather than 65 since 1982, and because of the development of forms of pre-retirement. The second lesson concerns the evolution of leisure- and visit-linked trips as opposed to shopping trips. The new generations of elderly people are more and more inclined to group their purchases in hypermarkets rather than use nearby stores. This evolution is made easier by greater motorisation, which actually reinforces it. 


\section{CONCLUSION}

What prospective lessons for the next twenty years is it therefore possible to get from these modal evolutions in travel behaviour of the elderly? The relationships between the social and economic environment on the one hand and transport demand on the other hand are multiple and complex, and it is wise to be very cautious. Moreover, the formalising of the different effects which we propose is simple and only concerns the use of the private car without going into its consequences on other transport modes. In order to be more explicative, it should notably take account of the behavioural differences of drivers according to the number of vehicles in the household, and distinguish between "young" and "old" retired people. Unfortunately, the size of the samples limits the degree of breakdown which we can hope to obtain. However, this analysis shows that among the effects of age, generation and period, the first two are more obvious in both the past and present evolutions in car-driving. Among the present generations of elderly people, the major changes come from motorisation which increased with the renewal of the generations, especially as far as women are concerned. This rise in the level of motorisation will no doubt continue with the arrival of new generations of women going into retirement - the present level of motorisation of women of 40 to 60 bears witness to this. On the other hand, the growth of car ownership as far as men are concerned is not going to go on much longer. In licence-holder use of cars, the major changes over the next 20 years will come from women. This increased domination by the car is going to have an opposite effect on the other modes of transport, especially on walking and public transport.

However, what remains to be evaluated is the size of the effects of ageing, which could affect the importance of de-motorisation for the elderly. At the present moment, just like the results pointed out by Madre and Gallez (1992), the profiles per cohort show that no de-motorisation is visible for men before the age of 80 . Women are less motorised already and the figures show that more of them abandon the use of the car. This evolution is only paradoxical in appearance, since this de-motorisation can often be explained by the decease of the husband who was the sole driver. The results presented by Jansson (1989) show that in the same way, in Sweden, de-motorisation is higher and starts earlier for women (from 70 onwards) than for men who keep on driving up till 75 at least. In the years to come more and more retired people are going to be two-car families. Are these couples going to give up one car? The reply to this question will enable us to have a better idea of the number of cars belonging to the elderly but also how easily elderly women are going to have access to a household car.

Other demographic, economic and social factors which are not easy to forecast will influence car ownership and modal choice for elderly people and will perturb the present trends.

From the demographic point of view, the future trends should logically show an ageing of the elderly population and a correlative increase in "older" elderly people to the detriment of "younger" elderly people. The continuing improvement in the state of health of elderly people may well cancel out this ageing effect. From an economic point of view, the financing of 
pensions and superannuation schemes is becoming more and more uncertain. But here again, the consequences may be variable - fall in income (which could have a depressive effect on car ownership), lengthening of active life (encouraging motorisation).

As far as society is concerned, future evolution of life styles of elderly people would seem to be just as difficult to forecast. The best we can do is to imagine certain trends, using present indicators: less-central place of residence, modification of the social composition and level of education of elderly people, more "active" retirement, for the first time, retirement for people who have only known the consumer and leisure society (Dirn, 1991). The future is, therefore, wide open.

\section{REFERENCES}

Bonnafous, A. (1992) La croissance du transport en question. Proceedings 12th International Symposium on Theory and Practice in Transport Economics, Lisbon, May 1992, Portugal.

Brög, W. (1992) Changements structurels de la population et impact sur la demande de transports de voyageurs. Table Ronde 88, 7-43.

Bussière, Y. (1992) Forecasting travel demand from age structure, urban sprawl and behaviour: the Montreal case, 1986-2011. 6th World Conference on Transport Research, Lyon, July 1992, France.

Chapleau, R. and Cote, J. (1989) Evolution de la mobilité des personnes de l'agglomération urbaine de Québec. 24 ${ }^{\text {th }}$ Annual Congress of the Association Québecoise des Transports Routiers, Jonquiére, March 1989, Canada.

Dirn, L. (1991) La Société Française en Tendances. PUF, Paris.

Gallez, C. and Madre, J.-L. (1992) Le parc automobile dans les années 2000 : méthodes démographiques et projection à long terme. Selected Proceedings of the 6th World Conference on Transport Research, Lyon, July 1992, France.

Greene, D.L. (1987) Long run vehicle travel prediction from demographic trends. Transporta-tion Research Record 1135, 5-12.

Guillemard, A.M. (1972) La Retraite, Une Mort Sociale. Sociologie des Conduites en Situa-tion de Retraite. Mouton, Paris.

Jansson, O.W. (1989) Car demand modelling and forecasting: a new approach. Journal of Transport Economics and Policy XXIII, 125-140. 
Kessler, D. and Masson, A. (1985) Cycle de Vie et Génération. Economica, Paris.

Kitamura, R. and Kostyniuk, L.P. (1987) Effects of aging and motorisation on travel behaviour: an exploration. Transportation Research Record 1135, 31-36.

Lambert, T. and Madre, J.-L. (1989) Prévisions à long terme du trafic automobile. Rapport $\mathrm{N}^{\circ}$ 60, INRETS, Arcueil.

Orfeuil, J.P. (1992) Changements structurels de la population et impact sur la demande de transports de voyageurs. Table Ronde 88, 45-106.

Paillat, P. (ed.), (1989) Passages de la Vie Active à la Retraite. PUF, Paris.

Pochet, P. (1995) Mobilité Quotidienne des Personnes Agées en Milieu Urbain: Evolutions Récentes et Perspectives. Thèse de Doctorat en Sciences Economiques, Université Lyon 2.

Robine, J.-M. and Mormiche, P. (1993) L'espérance de vie sans incapacité augmente. Insee Première 281, 1-4.

Van Den Broecke, A. (1992) La croissance du transport en question. Proceedings 12th Inter-national Symposium on Theory and Practice in Transport Economics, Lisbon, May 1992, Portugal.

Vibe, N. (1992) Changes in travel behaviour and car ownership in the Oslo region 1977-1990: potentials for further growth in the car fleet. 6th World Conference on Transport Research, Lyon, July 1992, France.

Wachs, M. (1979) Transportation for the Elderly. Changing Lifestyles, Changing Needs. University of California Press, Berkeley.

\section{NOTES}

${ }^{i}$ Expectation of life at birth is in constant progression and is presently near 82 for women and 73 for men. Furthermore, this progression is accompanied by a like lengthening of the period in which people are in good health. (Robine and Mormiche, 1993).

ii For each survey, approximately 4,000 individuals were polled on their travel behaviour during the previous day - between 400 and 700 over-sixties were thus surveyed each time.

iii The Grenoble public transport network is old-people friendly (easy access to tramway, free travel outside peak hours). 